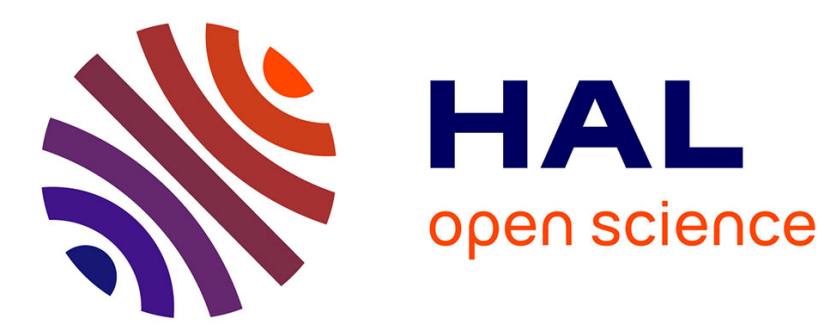

\title{
Electrical property of n-Hgo.sCdo.2Te plastically deformed
}

\author{
P. Girault, J-F. Barbot, C Blanchard
}

\section{To cite this version:}

P. Girault, J-F. Barbot, C Blanchard. Electrical property of n-Hgo.sCdo.2Te plastically deformed. Journal of Materials Science Letters, 1995, 14, pp.449 - 451. 10.1007/BF00274569 . hal-02471070

\section{HAL Id: hal-02471070 \\ https://hal-univ-rochelle.archives-ouvertes.fr/hal-02471070}

Submitted on 7 Feb 2020

HAL is a multi-disciplinary open access archive for the deposit and dissemination of scientific research documents, whether they are published or not. The documents may come from teaching and research institutions in France or abroad, or from public or private research centers.
L'archive ouverte pluridisciplinaire HAL, est destinée au dépôt et à la diffusion de documents scientifiques de niveau recherche, publiés ou non, émanant des établissements d'enseignement et de recherche français ou étrangers, des laboratoires publics ou privés. 


\title{
Electrical property of $\boldsymbol{n}-\mathrm{Hg}_{0.8} \mathrm{Cd}_{0.2} \mathrm{Te}$ plastically deformed
}

\author{
P. GIRAULT, J. F. BARBOT, C. BLANCHARD \\ Laboratoire de Métallurgie Physique, URA 131 CNRS, 40 Avenue du Recteur Pineau, 86022 Poitiers Cedex, \\ France
}

Establishing the electrical behaviour of extended defects in $\mathrm{Hg}_{1-x} \mathrm{Cd}_{x} \mathrm{Te}$ (MCT), is important for different reasons. Indeed, large areas of high quality epitaxial $\mathrm{HgCdTe}$ wafers are required for manufacturing planar photovoltaic infrared detector arrays, so large numbers of threading dislocations exist as a consequence of misfit stress. Recent investigations [1-3] have demonstrated that dislocations originating from material growth or array processing have a dramatic effect on the overall performance of devices. Note also that a deep level located at about $60 \mathrm{meV}$ above the valence band has been evidenced by deep level transient spectroscopy measurements in $p-\mathrm{Hg}_{0.78} \mathrm{Cd}_{0.22} \mathrm{Te}$ having a high dislocation density [4]. In this letter we report on some of our investigations of the electrical properties of $n$-type $\mathrm{Hg}_{0.8} \mathrm{Cd}_{0.2} \mathrm{Te}$ plastically deformed. Unfortunately, plastic deformation generates electrically active point defects in addition to dislocations; this is an extra obstacle for the understanding of the "pure" electrical effects of dislocations.

Experiments were made on $n$-type $\mathrm{Hg}_{0.8} \mathrm{Cd}_{0.2} \mathrm{Te}$ grown by the travelling heater method (THM) at SAT. As-grown samples with an initial dislocation density of about $1 \times 10^{5} \mathrm{~cm}^{-2}$ were single crystals cut in the shape of parallelepipeds of dimensions

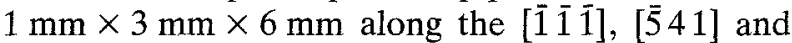
[12 3 ] directions. Measurements were done following the Van der Pauw method. The samples were placed on the cold finger of a cryogenerator (Leybold Heraus, RW2) whose temperature could be set within $1 \mathrm{~K}$ in the range $15-300 \mathrm{~K}$. After each electrical measurement series, samples were plastically deformed at room temperature by uniaxial stress along [12.3] axis $\left(\gamma \approx 6 \times 10^{-6} \mathrm{~s}^{-1}\right)$ using an Instron machine. Dislocations and point defects, introduced by plastic deformation, were then characterized by comparing the Hall coefficient and Hall mobility curves obtained before and after deformation. Before deformation, the donor $\left(N_{\mathrm{D}}^{+}\right)$and acceptor $\left(N_{\mathrm{A}}^{-}\right)$carrier concentrations were deduced from simultaneous fits of the experimental curves of $R_{\mathrm{H}}$ and $\mu_{\mathrm{H}}$, using the theory of electron mobility due to ionized impurity scattering. Moreover, at each temperature, the position of the Fermi levels $E_{\mathrm{F}}$ were calculated from the experimental values of $n$ according to Kane's model [5].

Fig. 1 shows the modulus of the Hall coefficient $\left|R_{\mathrm{H}}\right|$ and the Hall mobility $\mu_{\mathrm{H}}$ obtained before and after a small deformation $(\delta l / l=0.5 \%)$. As can be seen, the deformation leads to a diminution of the electron concentration. Consequently, if we assume
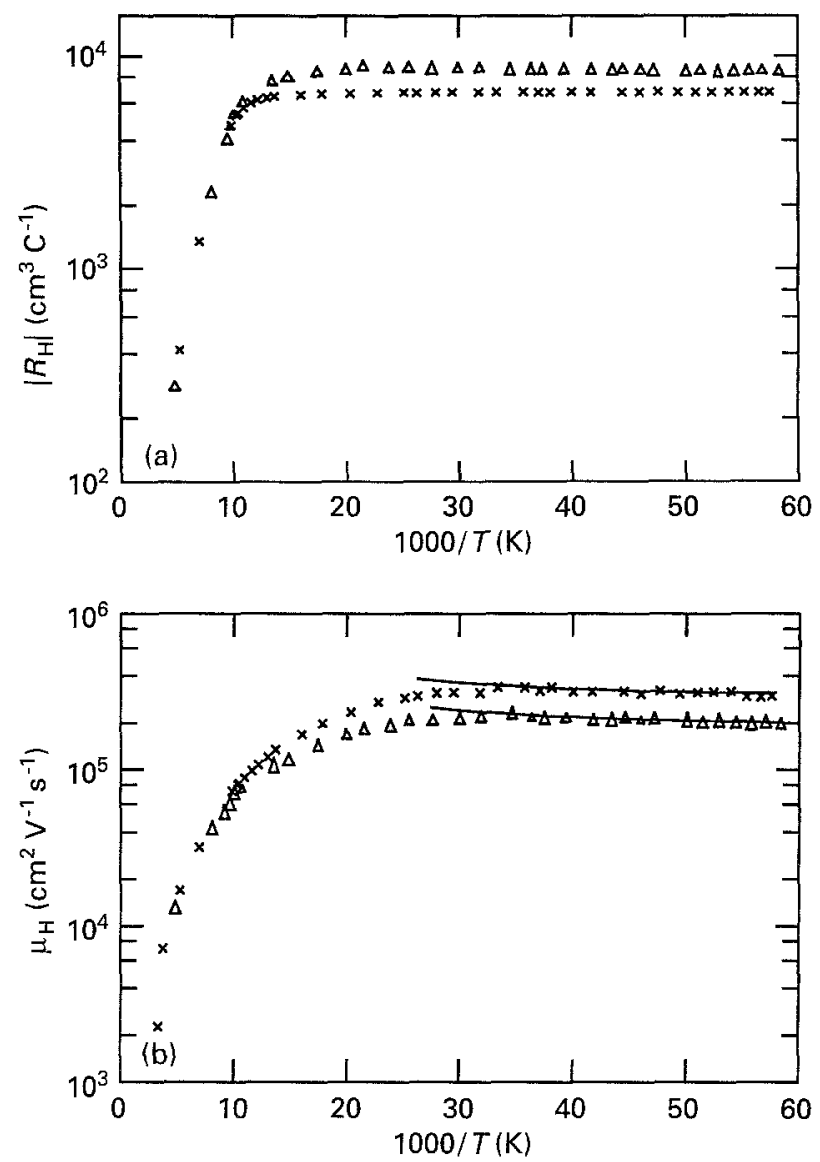

Figure 1 (a) Variation of the Hall coefficient $R_{\mathrm{H}}$ of $\mathrm{Hg}_{0.8} \mathrm{Cd}_{0.2} \mathrm{Te}$ against temperature obtained $(\times)$ before and $(\triangle)$ after a small deformation $(\delta l / l=0.5 \%)$. (b) Variation of the Hall mobility of $\mathrm{Hg}_{0.8} \mathrm{Cd}_{0.2} \mathrm{Te}$ against temperature obtained $(x)$ before and $(\triangle)$ after deformation $(\delta l / l=0.5 \%)$. The lines correspond to theoretical mobilities (undeformed sample: ionized impurity scattering; $E_{\mathrm{D}}^{0}-E_{\mathrm{v}}=10 \mathrm{meV}$ for deformed sample.

that acceptor and donor defects are both generated, acceptors are more efficient. Fig. 1b shows the reduction of the Hall mobility.

The concentration $n_{\mathrm{t}}$ of extra electrons trapped on $60^{\circ}$ dislocations is given by [6]:

$n_{\mathrm{t}}=2 D / b\left[1 /\left[1+2 \exp \left\{\left(E_{\mathrm{D}}^{*}-E_{\mathrm{F}}\right) / k T\right\}\right]-\xi\right]$

where $E_{\mathrm{D}}^{*}$ is the level of the charged dislocation, $\xi$ is the occupation rate $(\xi=1 / 4$ if the core atoms are $\mathrm{Hg}$ or $\mathrm{Cd}$ and $3 / 4$ if they are Te), $D$ is the dislocation density and $b$ the Burger's vector. The neutral level $E_{\mathrm{D}}^{0}$ of the dislocation is then obtained using the following expression $[6,7]$ :

$$
\begin{aligned}
E_{\mathrm{D}}^{*}= & E_{\mathrm{D}}^{0}+\left\{e^{2}\left[\ln \left(\gamma_{\mathrm{G}} / b\right)-1 / 2\right] /\left(2 \pi \varepsilon_{0} \varepsilon_{\mathrm{L}} b\right)\right. \\
& \left.+\alpha / \varepsilon_{\mathrm{L}}\right\} Y
\end{aligned}
$$


where $\gamma_{G}$ is the screening length and $\alpha$ is an intra-atomic interaction energy term [8]. In our calculations we have taken an average value $\alpha$ of $7.5 \mathrm{eV}$. In Fig. 2 the dislocation levels $E_{\mathrm{D}}^{0}$ and $E_{\mathrm{D}}^{*}$ are plotted as a function of the extra charge on dangling bonds $Y=n_{\mathrm{t}} b / D$ at a given temperature of $18 \mathrm{~K}\left(E_{\mathrm{g}} \approx 60 \mathrm{meV}\right)$. We can see that the $Y$ values are very small and that the nature of the ion core has little influence on $E_{\mathrm{D}}^{*}$.

After deformation the neutrality equation is given by:

$$
N_{\mathrm{D}}^{+}-N_{\mathrm{A}}^{-}-n+[\text { def. }]=X+[\text { def. }]=0
$$

assuming that deformation does not modify the ionization state of impurities already existing in the undeformed material. The term [def.] represents the electrically active defects introduced by plastic deformation. If only dislocations are responsible for the decrease of electron concentration, we then have $X=n_{t}$. At a temperature of $18 \mathrm{~K}$ we experimentally have $X(18 \mathrm{~K})=2 \times 10^{14} \mathrm{~cm}^{-3}$ and from Fig. 2 we can see that $Y$ must be in the range $3 \times 10^{-3}-3 \times 10^{-2}$. That leads to a dislocation density such that $3.2 \times 10^{8}<D\left(\mathrm{~cm}^{-2}\right)<3.2 \times 10^{9}$. However, if we use the Mathiessen rule, the experimental electron mobility induced by the defects is greater than that theoretically due to dislocation scattering alone [9]. To interpret our results, we have modified previous calculations on electron mobility due to dislocation scattering [8], taking into account the fact that the conduction band is non-parabolic and the semiconductor degenerated. Therefore, we must conclude that the reduction of the mobility (Fig. 1b) is mainly caused by the electrically point defects $\left(D_{\mathrm{p}}\right)$ introduced during the plastic deformation. In that case we have $X=n_{\mathrm{t}}+D_{\mathrm{p}}$, which can be written $X=K Y+D_{\mathrm{p}}$ with $K=D / b . D_{\mathrm{p}}$ is negative (or positive) if the point defects are donor (or acceptor) type. So, if we plot $X(T)$ against $Y(T)$ for a given position of $E_{\mathrm{D}}^{0}$ we must get a straight line, and thus the values of $D$ and $D_{p}$ can be derived; the point defects being supposed to be all ionized. Fig. 3 illustrates an example of such a curve for $E_{\mathrm{D}}^{0}-E_{\mathrm{v}}=10 \mathrm{meV}$. Using different positions of $E_{\mathrm{D}}^{0}$ we have found that

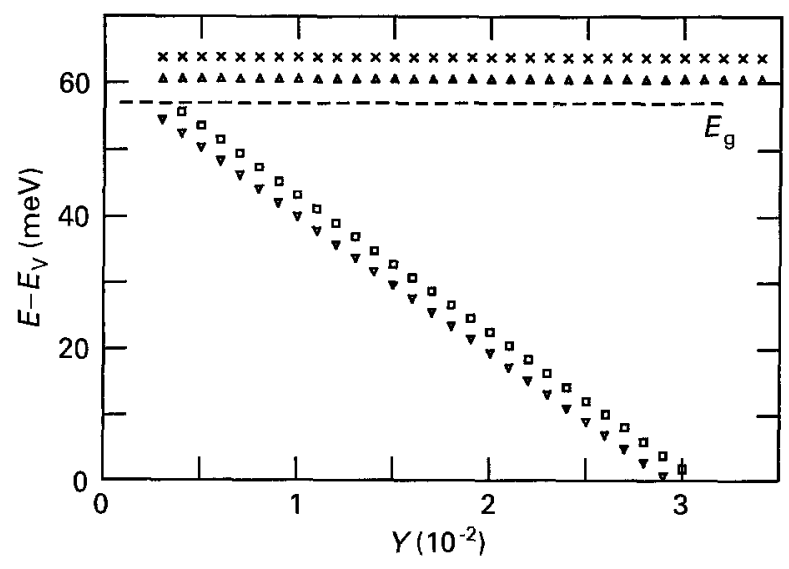

Figure 2 Dislocation levels $E_{\mathrm{D}}^{*}$ and $E_{\mathrm{D}}^{0}$ versus $Y=n_{\mathrm{t}} b / D$ for $T=18 \mathrm{~K}$ for $\mathrm{Hg}_{0.8} \mathrm{Cd}_{0.2} \mathrm{Te}$ deformed $\delta l / l=0.5 \%(\square), E_{\mathrm{D}}^{0} ;(\times)$ $E_{\mathrm{D}}^{*}: \xi=1 / 4 ;(\nabla), E_{\mathrm{D}}^{0},(\triangle), E_{\mathrm{D}}^{*}: \xi=3 / 4$.

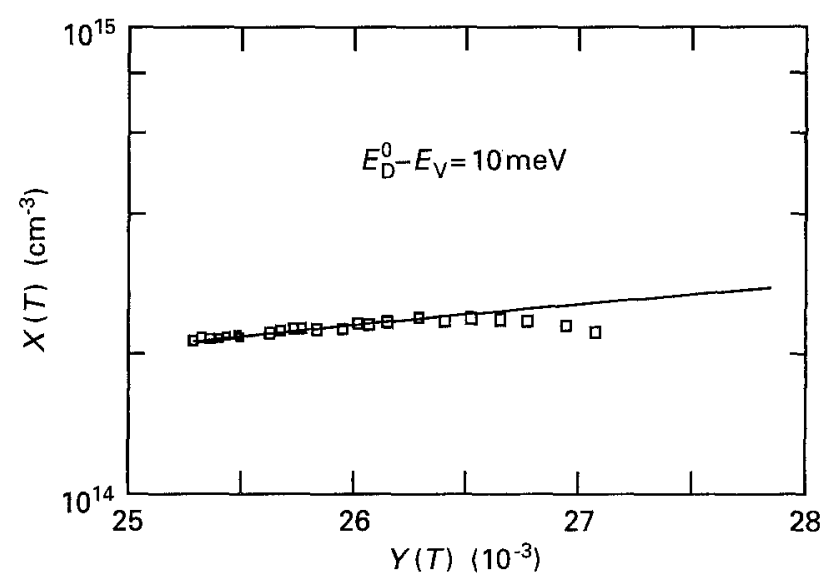

Figure 3 Variation of $X(T)$ against $Y(T)$ for $E_{\mathrm{D}}^{0}-E_{\mathrm{v}}=$ $10 \mathrm{meV}$

for $E_{\mathrm{D}}^{0}-E_{\mathrm{v}}$ lower than $40 \mathrm{meV}, D_{\mathrm{p}}$ is negative, indicating that the point defects are mostly donor type. In addition, the concentration $D_{\mathrm{p}}$ necessary to compensate the trapping by dislocations increases when $E_{\mathrm{D}}^{0}-E_{\mathrm{v}}$ decreases. This agrees with the fact that the smaller $E_{\mathrm{D}}^{0}-E_{\mathrm{v}}$, the more efficient is dislocation trapping.

For $E_{\mathrm{D}}^{0}-E_{\mathrm{v}}$ greater than $40 \mathrm{meV}, D_{\mathrm{p}}$ is positive and the point defects are mostly acceptor type.

In order to account for the reduction of the electron mobility observed in Fig. 1b, we must consider both types of point defects. Indeed, if all of the created point defects are donors (or acceptors), the calculated electron mobility due to the ionized impurities is then greater than the experimental one. So, we must have $D_{\mathrm{p}}=N_{\mathrm{A}}^{\text {(def.) }}$ $N_{\mathrm{D}}^{\text {(def.) }}$. For each position of $E_{\mathrm{D}}^{0}, N_{\mathrm{A}}^{\text {(def. }}$ and $N_{\mathrm{D}}^{\text {(def.) }}$ are determined by taking into account the electron mobility reduction. Fig. $1 \mathrm{~b}$ shows the fit of the mobility calculated for $E_{\mathrm{D}}^{0}-E_{\mathrm{V}}=10 \mathrm{meV}$. In this case we obtained $N_{\mathrm{D}}^{\text {(def.) }}=9.25 \times 10^{14} \mathrm{~cm}^{-3}$ and $N_{\mathrm{A}}^{\text {(def.) }}=4.95 \times 10^{14} \mathrm{~cm}^{-3}$. However, whatever $E_{\mathrm{D}}^{0}-E_{\mathrm{v}}$ is, it is always possible to find an $N_{\mathrm{D}}^{\text {(def.) }}$ and $N_{A}^{\text {(def.) }}$ pair which satisfies the electron mobility reduction. Consequently, we cannot deduce where the neutral dislocation level $E_{\mathrm{D}}^{0}$ is located in the band gap.

Fig. 4 is a plot of the Hall coefficient $\left|R_{\mathrm{H}}\right|$

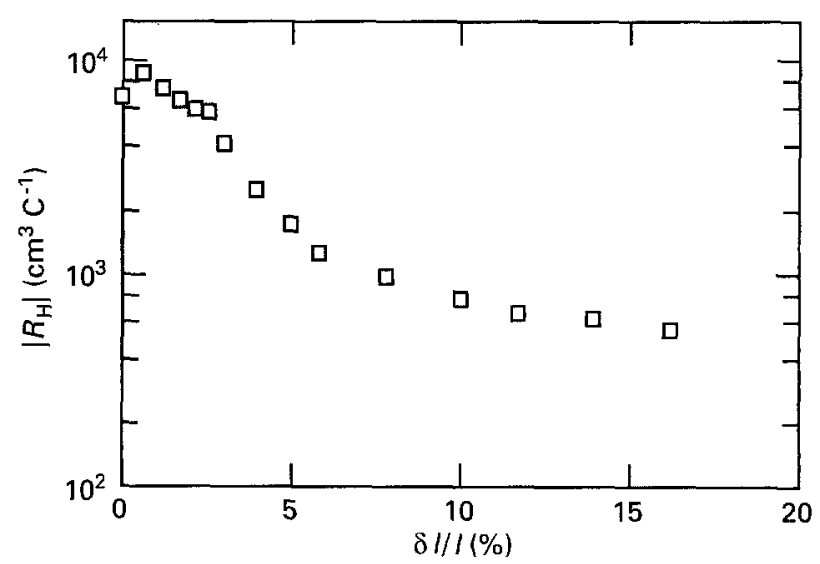

Figure 4 Modulus of the Hall coefficient $R_{\mathrm{H}}$ of $\mathrm{Hg}_{0.8} \mathrm{Cd}_{0.2} \mathrm{Te}$ against deformation $\delta l / l$ for a constant temperature $T=20 \mathrm{~K}$. 
measured at $20 \mathrm{~K}$ against the plastic deformation $\delta l / l$. We observe the decrease of $\left|R_{\mathrm{H}}\right|$ for deformations higher than $1 \%$. These data show an increase in the electron carrier concentration, i.e. in the donor concentration. This well agrees with the previous results of Tregildas et al. [10]. These authors observed on $n-\mathrm{Hg}_{0.78} \mathrm{Cd}_{0.22} \mathrm{Te}$ after $2 \%$ deformation an increase of the net donor density. Since the two types of point defects can be introduced in high concentrations, the interpretation of the results presented in Fig. 4 is more complicated than that developed for small deformation and only general features can be derived. The increase in carrier concentration is explained by the generation of mainly donor-type point defects which accompany the deformation. In this case, according to the small deformation $(\delta l / l=0.5 \%)$, we can reasonably suppose that the $E_{\mathrm{D}}^{0}$ level is located between $E_{\mathrm{v}}$ and $E_{\mathrm{v}}+40 \mathrm{meV}$ (donor-like point defects). To determine more precisely the position $E_{\mathrm{D}}^{0}$, we need to know exactly the density of electrically active dislocations. However, our results agree with a mid-gap level found in $\mathrm{p}-\mathrm{Hg}_{0.78} \mathrm{Cd}_{0.22} \mathrm{Te}$ having a high dislocation density [4] and also with the increase in donor concentration associated with the formation of dislocations observed in [2].

Lastly, note also that a possible model for the interaction mechanism between point defects and the moving dislocations has been proposed recently in InP [11]. Complexes can be dissociated in the space charge zone of charged dislocations, revealing a trail of point defects behind them. Such behaviour is compatible with our observations. At small deformations we only see the trapping by the dislocations whereas at higher deformations, the dislocation density remaining quite constant, the increase in carrier could be due to the donors associated with such a mechanism.

\section{References}

1. S. M. JOHNSON, D. R. RHIGER, J. P. ROSBECK, J. M. PETERSON, S. M. TAYLOR and M. E. BOYD, J. Vacuum Sci. Technol. B10 (1992) 1499.

2. R. S. LIST, ibid. B10 (1992) 1651.

3. R. S. LIST, J. Electron. Mater. 22 (1993) 1017.

4. M. C. CHEN and R. A. SCHIEBEL, J. Appl. Phys. 71 (1992) 5269.

5. E. O. KANE, J. Phys. Chem. Solids 1 (1957) 249.

6. R. MASUT, C. M. PENCHINA and J. L. FARVACQUE, J. Appl. Phys. $\mathbf{5 3}$ (1982) 4964.

7. D. FERRE, Thesis, University of Lille (1987).

8. J. L. FARVACQUE and D. FERRE, Rev. Phys. Appl. 15 (1980) 33.

9. P. GIRAULT, Thesis, University of Poitiers (1991).

10. J. L. TREGILDAS, T. L. POLGREEN and M. C. CHEN, J. Cryst. Growth 86 (1988) 460

11. A. ZOZIME, I. HANKE and W. SCHRÖTER, Phys. Status Solidi A 138 (1993) 445.

Received 18 May

and accepted 10 October 1994 